\title{
Utility of body mass index, waist circumference and waist-to-height ratio as screening tools for hyperglycemia in young people
}

Teresa Maria Bianchini de Quadros ${ }^{1,2,3}$, Alex Pinheiro Gordia ${ }^{1,2,3}$, Jorge Mota ${ }^{2}$, Luciana Rodrigues Silva ${ }^{3}$

${ }^{1}$ Curso de Educação Física da Universidade Federal do Recôncavo da Bahia, Amargosa, BA, Brasil ${ }^{2}$ Centro de Investigação em Atividade Física, Saúde e Lazer, da Faculdade de Ciências do Desporto da Universidade do Porto, Porto, Portugal ${ }^{3}$ Faculdade de Medicina, Programa de Pós-Graduação em Medicina e Saúde, Universidade Federal da Bahia, Salvador, BA, Brasil

\section{Correspondence to:}

Teresa Maria Bianchini de Quadros Av. Nestor de Melo Pita, 535 45300-000 - Amargosa, BA, Brasil tetemb@gmail.com

Received on Mar/21/2016 Accepted on Jul/4/2016

\begin{abstract}
Objectives: To evaluate the ability of BMI, WC and WHtR to discriminate hyperglycemia in young people, and to determine whether there is an increase in the accuracy with the addition of WC and/or WHtR to BMI. Subjects and methods: A cross-sectional study was conducted on 1,139 schoolchildren aged 6 to 17 years from Northeastern Brazil. Body weight, height, WC and fasting glucose levels were measured, and the $\mathrm{BMI}$ and $\mathrm{WH} \mathrm{tR}$ were calculated. The presence of hyperglycemia was defined as a fasting glucose level $\geq 100 \mathrm{mg} / \mathrm{dL}$. Results: The prevalence of hyperglycemia was $6.6 \%$. Strong correlations were observed between the anthropometric indicators studied (BMI vs. WC $=0.87$; $\mathrm{BMI}$ vs. $\mathrm{WHtR}=0.87 ; \mathrm{WC}$ vs. $\mathrm{WHtR}=0.90)$. Hyperglycemia was more likely to be present in young people with excess weight $(P R=1.70)$, high WC $(P R=1.85)$, and high WHtR $(P R=1.91)$. The accuracies to discriminate hyperglycemia were significant, but low, for the individual (BMI $=0.56 ; \mathrm{WC}=0.53 ; \mathrm{WHtR}$ $=0.55)$ and combined indicators $(\mathrm{BMI}+\mathrm{WC}=0.55 ; \mathrm{BMI}+\mathrm{WHtR}=0.55)$. Conclusion: Our findings do not support the use of $\mathrm{BMI}, \mathrm{WC}$ or $\mathrm{WH} \mathrm{tR}$ as screening tools for hyperglycemia in children and adolescents. Arch Endocrinol Metab. 2016;60(6):526-31
\end{abstract}

Keywords

Pediatric obesity; anthropometry; pediatrics; hyperglycemia; diabetes mellitus

\section{INTRODUCTION}

$\mathrm{T}$ he worldwide prevalence of overweight and obesity among children and adolescents has increased by about $47 \%$ in the last three decades (1). In parallel, a substantial increase has been observed in the prevalence of type 2 diabetes among young people (2). A growing body of evidence indicates that obese children and adolescents are more likely to present different cardiometabolic disorders (3), and that the maintenance of obesity from childhood to adulthood significantly increases the risk of type 2 diabetes (4).

Overweight and obesity are commonly evaluated in children and adolescents using the body mass index (BMI) because of its easy measurement and low cost. Additionally, reference values are available for comparison and the parameter permits continuous evaluation in adults (5). However, the relationship of this parameter with cardiometabolic alterations in young people can be questioned since the BMI estimates total body weight and not the quantity and distribution of fat. On the other hand, waist circumference (WC) and the waist-to-height ratio (WHtR) have gained ground in the evaluation of cardiometabolic risk factors in young people because these indicators propose to estimate central body fat $(6,7)$. A systematic review including 61 studies found that the deposition of central body fat in children and adolescents increases the cardiometabolic risk, irrespective of the definition of abdominal obesity and anthropometric method adopted (3).

Although anthropometric indicators are attractive tools for the evaluation of cardiometabolic risk, it is not clear whether BMI, WC and WHtR are able to discriminate hyperglycemia in children and adolescents, or whether WC and/or WHtR confer additional utility to BMI. Therefore, the objective of this study was twofold: 1) to evaluate the ability of BMI, WC and WHtR to discriminate hyperglycemia in young people, and 2 ) to determine whether the inclusion of WC and/or 
WHtR increases the accuracy of BMI to discriminate hyperglycemia in young people.

\section{SUBJECTS AND METHODS}

\section{Population and sample}

The present study is part of a school-based epidemiological study conducted in a city of Northeastern Brazil. The estimated population in 2012 was 34,845 inhabitants, with a human development index of 0.625 . The population consisted of school-age children and adolescents of both sexes ranging in age from 6 to 17 years (6.0 to 17.99 years). The students were enrolled in the $1^{\text {st }}$ to $9^{\text {th }}$ grades of elementary school and in the $1^{\text {st }}$ to $3^{\text {rd }}$ year of high school in public and private schools of the city. According to data from the Municipal Education Department, 7,708 students were enrolled in 42 schools in 2011, including 40 public schools $[13$ urban $(\mathrm{N}=5,207)$ and 27 rural $(\mathrm{N}=1,853)]$ and two private schools $(\mathrm{N}=648)$. The municipality studied comprises an area of $435,932 \mathrm{~km}^{2}$. For this reason, the Municipal Education Department divided the area of the municipality into six educational nuclei (one urban and five rural nuclei). Among the rural nuclei, the smallest possessed two schools and the largest seven schools in 2011. In the urban area, all schools were located in the same nucleus.

The representative sample size of the larger study was calculated using an estimated prevalence of $50 \%$ (for different outcomes), a 95\% confidence interval, and a precision of 3 percent points according to Luiz and Magnanini (8). The estimated sample size was 971 children and adolescent; 20\% of this number $(\mathrm{n}=194)$ was added to account for possible incomplete data of the subjects or refusal to participate in the data collection.

The sample was selected in two stages, in which the "school" was the primary sampling unit and the "student" the secondary sampling unit. In the first stage, cluster sampling of the schools was used, with proportional stratification by type of school (urban public, rural public, and private) and by educational nucleus for schools in the rural area (in order to guarantee the geographic distribution of the sample in the rural area). Five urban public schools, five rural public schools (one per nucleus studied), and one private school were selected by drawing lots. The estimated sample size per extract was proportional to that observed in the study population (urban public: $\mathrm{n}=787$; rural public: $\mathrm{n}=280$; private: $\mathrm{n}=98$ ). In the second stage, the students were selected by simple drawing lots considering the number of individuals necessary per school to compose the sample, so that the number would be proportional to the number of students enrolled in each school. The study protocol was approved by the Ethics Committee of Faculdade Maria Milza (Permit No. 126/2011). Only students who voluntarily accepted to participate and whose parents or legal guardian had signed the free informed consent form were included in the study.

\section{Instruments and procedures}

The data were collected between August 2011 and May 2012. The sociodemographic variables were obtained by self-report and included age, sex, and socioeconomic class. The last was estimated using the Brazilian Criterion of Economic Classification (9).

Body weight was measured with a Plenna digital scale (capacity of $150 \mathrm{~kg}$ ) to the nearest 100 g. Height was measured with a Seca portable stadiometer $(0$ to $220 \mathrm{~cm})$ fixed to the wall, to the nearest $0.1 \mathrm{~cm}$. The two variables were measured using standard techniques (10) and were used to calculate the BMI. Overweight and obesity were defined using the cut-off values proposed by Cole and cols. (11). WC was measured with a non-elastic measurement tape to the nearest $0.1 \mathrm{~cm}$ according to procedures recommended by the World Health Organization (12), and was classified as normal or elevated (13). Height and WC were used to calculate the WHtR. A WHtR $\geq 0.5$ was classified as high (14). Anthropometric assessment was performed in the morning by two examiners of the same sex as the students to avoid any embarrassment. The two examiners presented intra- and interobserver errors of less than $1 \%$ and $1.5 \%$ for all measures, which are acceptable according to the literature (15).

Venous blood samples $(10 \mathrm{~mL})$ for the measurement of blood glucose levels were collected at the schools in the morning after a 12-hour fast and a normal diet on the previous day. The samples were transported under refrigeration to the Nilson Lomanto Municipal Laboratory of Amargosa, Bahia, for analysis. Glucose levels were determined with an automatic biochemical analyzer (Biosystems ${ }^{\circledR}$, model Al5) by an enzymatic method based on the analysis of plasma fluoride. The presence of hyperglycemia was defined as a fasting 
glucose level $\geq 100 \mathrm{mg} / \mathrm{dL}$ as proposed by the American Diabetes Association (16).

\section{Statistical analysis}

The data were analyzed using the SPSS 15.0 and MedCalc programs. Descriptive analysis consisted of the calculation of mean, median, standard deviation, percentile, and frequency. Differences in glycemic profile, BMI, WC and WHtR between sexes and age groups (children: 6 to 9 years; adolescents: 10 to 17 years) were tested by the Mann-Whitney test $(\mathrm{p}<0.05)$. The partial correlation between the anthropometric indicators adjusted for sex and age was evaluated $(\mathrm{p}<$ $0.05)$. The prevalence ratio (PR), estimated by Poisson regression with robust variance, was used to verify the association of excess weight (overweight and obesity), elevated WC and high WHtR with hyperglycemia adjusted for sex, age and socioeconomic class. The Wald test was adopted to evaluate statistical significance $(\mathrm{p}<$ 0.05 ). The sensitivity, specificity and positive predictive value of excess weight (overweight and obesity) and high WC and WHtR were calculated. The power of the individual (BMI, WC, and WHtR) and combined indicators (BMI with WC and BMI with WHtR) to predict hyperglycemia was evaluated by constructing receiver operating characteristics (ROC) curves. The 95\% confidence intervals (95\% CI) were calculated and significance was attributed to areas under the ROC curve that showed a lower limit of the respective confidence intervals of 0.50 or higher. The difference in accuracy between the anthropometric indicators, alone or in combination, associated with hyperglycemia was calculated according to Hanley and McNeil (17).

\section{RESULTS}

The number of students evaluated was 1,139 , with $2.2 \%$ of losses due to refusal or absence on the day of data collection. The mean age was 11.51 years (3.33). Table 1 shows the differences in glycemia and anthropometric indicators according to sex and age group. Glycemia was higher in boys, and BMI, WC and WHtR were higher in girls. With respect to differences between children and adolescents, glycemia, BMI and WC were higher in adolescents, while WHtR was higher in children. The prevalence of hyperglycemia was $6.6 \%$ (95\% CI 5.3-8.3). Young people with hyperglycemia had median $\left(25^{\text {th }}, 75^{\text {th }}\right.$ percentiles $)$ glycemia, BMI, WC and WHtR of $103 \mathrm{mg} / \mathrm{dL}(101,106), 18.2 \mathrm{~kg} / \mathrm{m}^{2}$ $(16.38,20.28), 65.5 \mathrm{~cm}(60.0,74.2)$ and $0.46(0.42$, $0.51)$, respectively. The prevalence of overweight was $12.7 \%$ (95\% CI 10.9-14.8) and the prevalence of obesity was 3.2\% (95\% CI 2.3-4.3). High WC and WHtR were observed in $17.8 \%$ (95\% CI 15.7-20.2) and $19.7 \%$ (95\% CI 17.5-22.1) of the students, respectively.

Strong correlations adjusted for age and sex were observed between all anthropometric indicators (BMI vs. $\mathrm{WC}=0.87 ; \mathrm{BMI}$ vs. $\mathrm{WHtR}=0.87 ; \mathrm{WC}$ vs. $\mathrm{WHtR}$ $=0.90)$. In multivariate logistic regression analysis adjusted for sex, age and socioeconomic condition, hyperglycemia was more likely to be present in young people with excess weight $(\mathrm{PR}=1.70,95 \% \mathrm{CI} 1.03$ $2.85, \mathrm{p}=0.04)$, elevated WC $(\mathrm{PR}=1.85,95 \%$ CI 1.13 $3.03, \mathrm{p}=0.01)$, and high WHtR $(\mathrm{PR}=1.91,95 \% \mathrm{CI}$ $1.17-3.12, \mathrm{p}=0.01$ ).

The sensitivity, specificity and positive predictive value were $24.3 \%, 84.5 \%$ and $10.0 \%$ for excess weight, $28.4 \%, 82.7 \%$ and $10.4 \%$ for $\mathrm{WC}$, and $31.1 \%, 80.8 \%$

Table 1. Glycemic profile and anthropometric indicators in the children and adolescents studied according to sex and age group. Northeastern Brazil, 2011-2012

\begin{tabular}{|c|c|c|c|c|c|}
\hline & $\mathbf{n}$ & Glycemia $(m g / d L)^{a}$ & BMI $\left(\mathrm{kg} / \mathrm{m}^{2}\right)^{\mathrm{a}}$ & WC $(\mathrm{cm})^{\mathrm{a}}$ & WHtR $^{\mathrm{a}}$ \\
\hline \multicolumn{6}{|l|}{ Sex } \\
\hline Male & 506 & $90(85,94)$ & $17.00(15.60,19.40)$ & $63.0(56.5,70.0)$ & $0.44(0.42,0.46)$ \\
\hline Female & 633 & $88(83,93)$ & $18.10(15.90,20.80)$ & $66.9(59.5,73.6)$ & $0.46(0.43,0.49)$ \\
\hline$p^{b}$ & & 0.003 & 0.001 & 0.001 & 0.001 \\
\hline \multicolumn{6}{|l|}{ Age group } \\
\hline Children (6 to 9 years) & 363 & $88(83,93)$ & $15.60(14.60,17.10)$ & $56.4(53.0,60.4)$ & $0.45(0.43,0.48)$ \\
\hline Adolescents (10 to 17 years) & 776 & $89(85,94)$ & $18.80(16.74,21.20)$ & $69.0(63.4,74.8)$ & $0.45(0.42,0.48)$ \\
\hline$p^{b}$ & & 0.033 & 0.001 & 0.001 & 0.041 \\
\hline Total & 1.139 & $89(84,94)$ & $17.50(15.70,20.10)$ & $65.5(58.0,72.3)$ & $0.45(0.42,0.48)$ \\
\hline
\end{tabular}

BMI: body mass index; WC: waist circumference; WHtR: waist-to-height ratio.

a Median (25

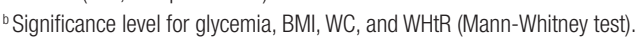


and $10.3 \%$ for $\mathrm{WHtR}$, respectively. The accuracies to discriminate hyperglycemia were significant, but low, for all indicators studied. No significant differences were observed between individual and combined anthropometric indicators (Table 2).

Table 2. Accuracy of the anthropometric indicators for hyperglycemia screening in the children and adolescents studied. Northeastern Brazil, 2011-2012

\begin{tabular}{lcc}
\hline Anthropometric indicator & AUC & $\mathbf{9 5 \%} \mathbf{~ c ~}$ \\
\hline BMl $\left(\mathrm{kg} / \mathrm{m}^{2}\right)$ & 0.56 & $0.53-0.59$ \\
WC $(\mathrm{cm})$ & 0.53 & $0.50-0.56$ \\
WHtR & 0.55 & $0.52-0.58$ \\
BMI $\left(\mathrm{kg} / \mathrm{m}^{2}\right)$ and WC $(\mathrm{cm})$ & 0.55 & $0.52-0.58$ \\
BMl $\left(\mathrm{kg} / \mathrm{m}^{2}\right)$ and WHtR & 0.55 & $0.52-0.58$ \\
\hline
\end{tabular}

BMI: body mass index; WC: waist circumference; WHtR: waist-to-height ratio; AUC: area under the curve; $95 \% \mathrm{Cl}$ : 95\% confidence interval.

\section{DISCUSSION}

The use of simple, easily obtainable and inexpensive measures such as body weight, height and WC for the screening of cardiometabolic risk factors in young people is a promising strategy for the prevention and early diagnosis of diseases such as type 2 diabetes. In this respect, the objective of this study was to evaluate the ability of BMI, WC and WHtR to discriminate hyperglycemia in the pediatric population, and to determine whether the inclusion of WC and/or WHtR increases the accuracy of BMI to discriminate hyperglycemia. Our results showed that the anthropometric indicators evaluated were associated with hyperglycemia. However, BMI, WC and WHtR were not efficient in screening for hyperglycemia in young people because their accuracy was poor. Furthermore, the addition of the indicators of abdominal obesity to BMI did not increase the ability of this index to discriminate young people with and without hyperglycemia.

In recent years, some authors have suggested the use of WC and WHtR for the evaluation of obesity and associated health problems in children and adolescents $(6,7)$. However, others argue that there is not sufficient evidence to use these indicators instead of BMI $(18,19)$. In fact, the average increase in the BMI of children and adolescents has been accompanied by an even more marked increase in WC (20). There might be additional advantages when this measure is corrected for height, such as the absence of a measurement unit, the lack of need for a specific reference population, and the possibility to use a single cut-off to discriminate excess fat in both young people and adults $(\mathrm{WHtR}=0.5)$. However, evidence indicates that measuring height in addition to WC has no additional benefit for predicting cardiometabolic risk (21), and it may not be sufficient to adjust WC for height during the growth periods in childhood and adolescence because of the considerable residual correlation between height and WHtR (ranging from 0.29 to 0.36 ) (22). Furthermore, at least four different anatomical sites are commonly used to measure WC $(23,24)$, a fact that can produce different prevalences of abdominal obesity (23) and impair the comparison between studies. Moreover, the magnitude of the association between WC and cardiometabolic risk factors in young people seems to be influenced by the site of measurement of this parameter (24).

With respect to the evaluation of general obesity, BMI has been the most used anthropometric indicator for decades. This index has wide applicability and is associated with less inter- and intraobserver error than demonstrated for other measures of obesity in young people (25). The calculation of BMI, which can be considered an obstacle to the use of this index by the population, can nowadays be performed easily using calculators available in electronic devices used in everyday life (e.g., mobile phones). Calculating BMI with a calculator can even be faster than to obtain other anthropometric measures of obesity. On the other hand, although children and adolescents with a high BMI also tend to have high levels of body fat, the BMI does not differentiate lean mass from fat mass and may therefore be considered an inaccurate indicator of body fat, especially among young people with normal or relatively low levels of body fat (26).

Previous studies analyzing anthropometric measures as predictors of hyperglycemia in children and adolescents also observed poor accuracies, ranging from 0.44 to 0.51 for BMI, from 0.44 to 0.52 for WC, and from 0.50 to 0.57 for WHtR (27-30). It is well known that excess body fat is associated with different physiological and pathological states, including alterations in glucose metabolism (31). In this respect, both the amount of total body fat and fat distribution exert moderate effects on glucose metabolism, with a greater effect being observed for abdominal visceral fat (31). Although attractive because they are noninvasive methods to estimate obesity, anthropometric indicators are not exact measures of total body fat and fat distribution (especially abdominal visceral 
fat) in children and adolescents (19). This limitation of the anthropometric method, in conjunction with the latency period of hyperglycemia, may explain at least in part the poor accuracies of BMI, WC and WHtR to discriminate hyperglycemia in young people. The phenomenon of "metabolically healthy obesity" observed among adults as well as children and adolescents (32) may also be a confounding factor in the relationship between anthropometric indicators and glycemia. Furthermore, factors not evaluated in the present study, such as the duration of obesity and the rate of recent weight gain/ loss, may play an important role in altered glucose metabolism, irrespective of the current weight status (29).

Although the relationship between obesity and hyperglycemia/type 2 diabetes is well established in adults (33), in the pediatric population this subject requires further research. The PR obtained in this study indicated that overweight and obese young people were more likely to have hyperglycemia, irrespective of the anthropometric method used. Some studies also observed this association $(7,34)$, while others did not demonstrate it $(27,29)$. These divergences between the results of studies might be related to the characteristics of the samples such as age group, socioeconomic condition and lifestyle of the subjects studied, as well as methodological aspects, especially the criterion used to define hyperglycemia. In the present study, although a higher PR was observed for WHtR, the magnitude of the associations was similar $(\mathrm{WHtR}=1.91$, WC $=$ 1.85 and $\mathrm{BMI}=1.70)$. It should be mentioned that $\mathrm{PR}$ is not a statistical analysis that distinguishes between the presence and absence of disease; it only suggests an association between exposure and outcome and should therefore not be used to define whether a method is adequate to screen for a certain disease.

Strong correlations were observed in the present study between the three anthropometric indicators, in agreement with the findings of previous studies $(18,19)$. Katzmarzyk and Bouchard (19) analyzed the correlation of total and visceral body fat with BMI and WC in children aged 5 to 18 years and found strong correlations between total and visceral body fat and the two anthropometric indicators. Accordingly, it can be expected that little additional information be obtained when adding WC and/or WHtR to BMI, as confirmed by our accuracy analysis. Chiolero and cols. (18) also observed that the addition of WHtR to BMI did not confer additional discriminatory power for elevated blood pressure in children. Taken together, the results suggest caution to state that WC or WHtR is a better substitute of BMI for the evaluation of body fat, or that the addition of these indicators to BMI improves the screening capacity for cardiometabolic risk in the pediatric population.

A strength of our study is the evaluation of the association of three simple anthropometric indicators with glycemia in a school-based probability sample consisting of children and adolescents of both genders from a developing country. Additionally, to our knowledge, there are no other studies investigating the addition of WC and WHtR to BMI in an attempt to improve the prediction of hyperglycemia in the pediatric population. However, this study has some limitation that need to be considered. A single measurement of fasting glucose levels, although suitable for populational studies, does not reflect the initial alterations in glucose homeostasis nor does it differentiate young people with and without impaired glucose tolerance/type 2 diabetes until significant deterioration in glucose metabolism has occurred (35). The cross-sectional design did not permit to establish cause-effect relationships since the exposure and outcome variables were collected simultaneously. Therefore, studies monitoring changes in body fat and glucose metabolism in young people over time are needed to gain further insight into this topic.

In conclusion, the anthropometric indicators studied were not useful to screen for hyperglycemia; however, obese children and adolescents were more likely to have hyperglycemia. In this respect and taking into consideration that obesity theoretically precedes hyperglycemia, BMI, WC and WHtR should continue to be used for the evaluation of overweight and obesity and consequent monitoring of metabolic diseases at early ages.

Author contribution: TMBQ, and APG designed the study, directed implementation and data collection, analyzed the data, and drafted the manuscript. LRS, and JM edited the manuscript for intellectual content and provided critical comments on the manuscript.

Acknowledgement: we thank the Municipal Education and Health Departments of Amargosa, Bahia, Brazil, for help with the study. This work was supported by Fundação de Amparo à Pesquisa do Estado da Bahia - Fapesb, Brazil, Coordenação de Aperfeiçoamento de Pessoal de Nível Superior - Capes, Brazil, and Fundação para a Ciência e a Tecnologia - FCT, Portugal (FCT:UID/DTP/00617/2013).

Disclosure: no potential conflict of interest relevant to this article was reported. 


\section{REFERENCES}

1. Ng M, Fleming T, Robinson $M$, Thomson B, Graetz N, Margono $C$, et al. Global, regional, and national prevalence of overweight and obesity in children and adults during 1980-2013: a systematic analysis for the Global Burden of Disease Study 2013. Lancet. 2014;384(9945):766-81.

2. Dabelea D, Mayer-Davis EJ, Saydah S, Imperatore G, Linder B, Divers J, et al. Prevalence of type 1 and type 2 diabetes among children and adolescents from 2001 to 2009. JAMA. 2014;311(17):1778-86.

3. Kelishadi R, Mirmoghtadaee P, Najafi H, Keikha M. Systematic review on the association of abdominal obesity in children and adolescents with cardio-metabolic risk factors. J Res Med Sci. 2015;20(3):294-307.

4. Petkeviciene J, Klumbiene J, Kriaucioniene V, Raskiliene A, Sakyte E, Ceponiene I. Anthropometric measurements in childhood and prediction of cardiovascular risk factors in adulthood: Kaunas cardiovascular risk cohort study. BMC Public Health. 2015;15:218.

5. de Onis M, Onyango AW, Borghi E, Siyam A, Nishida C, Siekmann J. Development of a WHO growth reference for school-aged children and adolescents. Bull World Health Organ. 2007;85(9):660-7.

6. Kuba VM, Leone C, Damiani D. Is waist-to-height ratio a useful indicator of cardio-metabolic risk in 6-10-year-old children? BMC Pediatr. 2013;13:91.

7. Schwandt P, Bertsch T, Haas GM. Anthropometric screening for silent cardiovascular risk factors in adolescents: The PEP Family Heart Study. Atherosclerosis. 2010;211(2):667-71.

8. Luiz RR, Magnanini MMF. A lógica da determinação do tamanho da amostra em investigações epidemiológicas. Cad Saúde Colet. 2000;8(2):9-28.

9. Brazilian Association of Research Companies - ABEP, 2011. Criterion Standard Classification of Economic Brazil/2011. [cited April 26th 2012]. Available from: <http://www.abep.org/novo/ Content.aspx?Content|D=301>.

10. Gordon CC, Chumlea WCC, Roche AF. Stature, recumbent length, and weight. In: Lohman TG, Roche AF, Martorell R, editors. Anthropometric standardization reference manual. Champaign: Human Kinetics; 1988. p. 3-8.

11. Cole TJ, Bellizzi MC, Flegal KM, Dietz WH. Establishing a standard definition for child overweight and obesity worldwide: international survey. BMJ. 2000;320(7244):1240-3.

12. World Health Organization. Measuring obesity: classification and distribution of anthropometric data. Copenhagen: World Health Organization (Nutr UD, EUR/ICP/NUT 125); 1988.

13. Fernandez JR, Redden DT, Pietrobelli A, Allison DB. Waist circumference percentiles in nationally representative samples of African-American, European-American, and Mexican-American children and adolescents. J Pediatr. 2004;145(4):439-44.

14. Maffeis C, Banzato C, Talamini G, Obesity Study Group of the Italian Society of Pediatric E, Diabetology. Waist-to-height ratio, a useful index to identify high metabolic risk in overweight children. J Pediatr. 2008;152(2):207-13.

15. Pederson D, Gore C. Anthropometry measurement error. In: Norton K, Olds T, eds. Anthropometrica: a textbook of body measurement for sports and health courses. Sydney: University of New South Wales Press; 1996. p. 77-96.

16. American Diabetes Association. Diagnosis and classification of diabetes mellitus. Diabetes Care. 2011;34:62-9.

17. Hanley JA, McNeil BJ. A method of comparing the areas under receiver operating characteristic curves derived from the same cases. Radiology. 1983;148(3):839-43.

18. Chiolero A, Paradis G, Maximova K, Burnier M, Bovet P. No use for waist-for-height ratio in addition to body mass index to identify children with elevated blood pressure. Blood Press. 2013;22(1):1720.

19. Katzmarzyk PT, Bouchard C. Where is the beef? Waist circumference is more highly correlated with BMI and total body fat than with abdominal visceral fat in children. Int J Obes (Lond). 2014;38(6):753-4.

20. Zhao YQ, Zu P, Zhu P, Sun Y, Wu XY, Xu SJ, et al. Changes in BMI and waist circumference among primary and secondary school students from 2005 to 2010 in Anhui, China. Ann Hum Biol. 2014;41(3):201-4.

21. Kodama S, Horikawa C, Fujihara K, Heianza Y, Hirasawa R, Yachi $Y$, et al. Comparisons of the strength of associations with future type 2 diabetes risk among anthropometric obesity indicators, including waist-to-height ratio: a meta-analysis. Am J Epidemiol. 2012;176(11):959-69.

22. Tybor DJ, Lichtenstein AH, Dallal GE, Must A. Waist-to-height ratio is correlated with height in US children and adolescents aged 2-18 years. Int J Pediatr Obes. 2008;3(3):148-51.

23. Mason C, Katzmarzyk PT. Variability in waist circumference measurements according to anatomic measurement site. Obesity (Silver Spring). 2009;17(9):1789-95.

24. Johnson ST, Kuk JL, Mackenzie KA, Huang TT, Rosychuk RJ, Ball GD. Metabolic risk varies according to waist circumference measurement site in overweight boys and girls. J Pediatr. 2010;156(2):247-52 e1.

25. De Miguel-Etayo P, Mesana MI, Cardon G, De Bourdeaudhuij I, Gozdz M, Socha P, et al. Reliability of anthropometric measurements in European preschool children: the ToyBox-study. Obes Rev. 2014;15(Suppl 3):67-73.

26. Bray GA, DeLany JP, Volaufova J, Harsha DW, Champagne C. Prediction of body fat in 12-y-old African American and white children: evaluation of methods. Am J Clin Nutr. 2002;76(5):98090.

27. Kruger HS, Faber M, Schutte AE, Ellis SM. A proposed cutoff point of waist-to-height ratio for metabolic risk in African township adolescents. Nutrition. 2013;29(3):502-7.

28. Moraes MM, Veiga GV. Accuracy of body fat and waist circumference in predicting metabolic abnormalities indicating cardiovascular risk in adolescents. Arq Bras Endocrinol Metabol. 2014;58(4):341-51.

29. Morandi A, Miraglia Del Giudice E, Martino F, Martino E, Bozzola M, Maffeis C. Anthropometric indices are not satisfactory predictors of metabolic comorbidities in obese children and adolescents. J Pediatr. 2014;165(6):1178-1183 e2.

30. Vieira AC, Alvarez MM, Kanaan S, Sichieri R, Veiga GV. Body mass index for predicting hyperglycemia and serum lipid changes in Brazilian adolescents. Rev Saude Publica. 2009;43(1):44-52.

31. Muller MJ, Lagerpusch $M$, Enderle J, Schautz B, Heller $M$, Bosy-Westphal A. Beyond the body mass index: tracking body composition in the pathogenesis of obesity and the metabolic syndrome. Obes Rev. 2012;13(Suppl 2):6-13.

32. Bluher S, Schwarz P. Metabolically healthy obesity from childhood to adulthood - Does weight status alone matter? Metabolism. 2014;63(9):1084-92.

33. Bell JA, Kivimaki M, Hamer M. Metabolically healthy obesity and risk of incident type 2 diabetes: a meta-analysis of prospective cohort studies. Obes Rev. 2014;15(6):504-15.

34. Suarez-Ortegon MF, Ortega-Avila JG, Ordonez-Betancourth JE, Aguilar-de Plata C. Adiposity markers and cardiovascular risk in urban Colombian adolescents: heterogeneity in association patterns. Metabolism. 2013;62(7):1000-7.

35. Velasquez-Mieyer $\mathrm{P}$, Neira $\mathrm{CP}$, Nieto $\mathrm{R}$, Cowan PA. Obesity and cardiometabolic syndrome in children. Ther Adv Cardiovasc Dis. 2007;1(1):61-81. 